OPEN ACCESS

Edited by:

Olivia Gosseries,

University of Liège, Belgium

Reviewed by:

Martin Monti,

UCLA Department of Psychology,

United States

Yuzheng Hu,

National Institute on Drug Abuse (NIDA), United States

*Correspondence: Lorina Naci nacil@tcd.ie

Specialty section:

This article was submitted to Applied Neuroimaging,

a section of the journal

Frontiers in Neurology

Received: 26 January 2018

Accepted: 06 June 2018

Published: 27 June 2018

Citation:

Haugg A, Cusack $R$,

Gonzalez-Lara LE, Sorger B, Owen AM and Naci L (2018) Do

Patients Thought to Lack

Consciousness Retain the Capacity for Internal as Well as External

Awareness? Front. Neurol. 9:492. doi: 10.3389/fneur.2018.00492

\section{Do Patients Thought to Lack Consciousness Retain the Capacity for Internal as Well as External Awareness?}

\author{
Amelie Haugg ${ }^{1,2}$, Rhodri Cusack ${ }^{3}$, Laura E. Gonzalez-Lara ${ }^{4}$, Bettina Sorger ${ }^{5}$, \\ Adrian M. Owen ${ }^{4}$ and Lorina $\mathrm{Naci}^{3 *}$ \\ ${ }^{1}$ Department of Psychiatry, Psychotherapy and Psychosomatics, Psychiatric Hospital, University of Zurich, Zurich, \\ Switzerland, ${ }^{2}$ Neuroscience Center Zurich, Swiss Federal Institute of Technology, University of Zurich, Zurich, Switzerland, \\ ${ }^{3}$ School of Psychology, Trinity College Institute of Neuroscience, Trinity College Dublin, Dublin, Ireland, ${ }^{4}$ The Brain and Mind \\ Institute, University of Western Ontario, London, ON, Canada, ${ }^{5}$ Faculty of Psychology and Neuroscience, Maastricht \\ University, Maastricht, Netherlands
}

It is well established that some patients, who are deemed to have disorders of consciousness, remain entirely behaviorally non-responsive and are diagnosed as being in a vegetative state, yet can nevertheless demonstrate covert awareness of their external environment by modulating their brain activity, a phenomenon known as cognitive-motor dissociation. However, the extent to which these patients retain internal awareness remains unknown. To investigate the potential for internal and external awareness in patients with chronic disorders of consciousness (DoC), we asked whether the pattern of juxtaposition between the functional time-courses of the default mode (DMN) and fronto-parietal networks, shown in healthy individuals to mediate the naturally occurring dominance switching between internal and external aspects of consciousness, was present in these patients. We used a highly engaging movie by Alfred Hitchcock to drive the recruitment of the fronto-parietal networks, including the dorsal attention (DAN) and executive control (ECN) networks, and their maximal juxtaposition to the DMN in response to the complex stimulus, relative to rest and a scrambled, meaningless movie baseline condition. We tested a control group of healthy participants $(N=13 / 12)$ and two groups of patients with disorders of consciousness, one comprised of patients who demonstrated independent, neuroimaging-based evidence of covert external awareness $(N=8)$, and the other of those who did not $(N=8)$. Similarly to the healthy controls, only the group of patients with overt and, critically, covert external awareness showed significantly heightened differentiation between the DMN and the DAN in response to movie viewing relative to their resting state time-courses, which was driven by the movie's narrative. This result suggested the presence of functional integrity in the DMN and fronto-parietal networks and their relationship to one another in patients with covert external awareness. Similar to the effect in healthy controls, these networks became more strongly juxtaposed to one another in response to movie viewing relative to the baseline 
conditions, suggesting the potential for internal and external awareness during complex stimulus processing. Furthermore, our results suggest that naturalistic paradigms can dissociate between groups of DoC patients with and without covert awareness based on the functional integrity of brain networks.

Keywords: functional Magnetic Resonance Imaging (fMRI), functional connectivity, disorders of consciousness, naturalistic stimulation, movie watching, conscious information processing

\section{INTRODUCTION}

In the last decade, a population of patients has been identified who are demonstrably conscious, but entirely unable to speak or move willfully in any way, and remain behaviorally nonresponsive for several years (1-8). Following severe brain-injury, patients may manifest a spectrum of behavioral non-responsivity, from a complete absence to minimal and inconsistent willful behavioral responses (9-11). Patients who do not show any willful behavioral responses on repeated behavioral examinations, are thought to lack awareness of oneself and one's environment and are clinically diagnosed to be in a vegetative state (VS) (12), also known as the "unresponsive wakefulness syndrome" (UWS) (13). The clinical, behavioral assessment of non-responsive patients is particularly difficult because of its reliance on the subjective interpretation of inconsistent behaviors, which are often limited by motor constraints, and can result in high misdiagnosis rates (up to $43 \%$ ) (14). Recent studies have shown that, despite the complete absence of external signs of awareness, a significant minority $(\sim 14-19 \%)$ of patients thought to be in a VS are able to demonstrate conscious awareness by modulating their brain activity $(2,15)$ in different types of neuroimaging paradigms [e.g., $(1,3-5,7,8)]$, a phenomenon captured by the recentlycoined term "cognitive motor dissociation" (CMD) (16). Despite these advances, the mental life of behaviorally non-responsive patients-particularly their capacity to have similar experiences as healthy individuals in response to everyday life events that involve both their awareness of oneself and awareness of one's environment - had until recently remained largely unknown and inaccessible to empirical investigation.

To address this challenge, Naci et al. $(7,17,18)$ developed a movie-viewing paradigm for the investigation of conscious experiences of behaviorally non-responsive patients who may retain covert awareness. Movie viewing is highly suited to testing populations that exhibit large fluctuations in arousal, impaired motor control and compromised attention span, because, by creating an immersive experience, it naturally engages attention and various cognitive processes that lead to reduced movement in the scanner (19) and recruitment of strong brain activity that is synchronized across different individuals (7, 18, 20-23). Naci and colleagues focused on the assessment of executive function-a high-level cognitive function that requires conscious awareness-while participants watched a brief ( $8 \mathrm{~min}$ ) and highly engaging movie by Alfred Hitchcock. The investigators found that the movie's executive demands, assessed quantitatively and qualitatively in independent control groups, predicted similar activity across individual participants in the frontal and parietal cortex, regions that support executive processing (25-29). Thus, the time-course of the fronto-parietal activation provided a template for decoding whether behaviorally non-responsive patients have similar cognitive experiences to healthy individuals in response to the executive demands of the movie. Using this approach, Naci and colleagues demonstrated that a patient who had been behaviorally non-responsive and thought to lack consciousness for 16 years was consciously aware and could continuously engage in complex thoughts about real-world events unfolding over time (7). Thus, they provided strong evidence that some patients who are entirely behaviorally nonresponsive can retain conscious awareness of their external environment $(17,24)$.

However, awareness of oneself, an aspect of consciousness routinely tested for at the patient's bedside, is more elusive and harder to measure, even in patients who demonstrate awareness of their external environment, such as those thought to be in a minimally conscious state (30). Traditionally, awareness of oneself, or internal awareness, has been assessed through self-report and, as a result, it is challenging to measure in its complete absence. Therefore, the extent to which some DoC patients, especially those who remain entirely behaviorally nonresponsive and are diagnosed to be in a VS, are capable of internal awareness remains unclear. In the healthy brain, the focus of conscious awareness is thought to switch naturally over time between its internal and external aspects (31-33), a relationship mediated by the fluctuating juxtaposition or anti-correlation of functional time-courses of the default mode network (DMN) and fronto-parietal networks, as observed in the resting state (34-36). Although recent studies suggest a role for the DMN in facilitating goal-oriented behavior (3739), this network has been shown to support a variety of internally-driven processes, including autobiographical memory, imagination, thinking about the self (40-46), and internal awareness $(31,33)$. Furthermore, the DMN decreases in activity when attention is directed externally $(34,47,48)$, but increases in response to introspectively-oriented cognitive processes $(44,46)$. By contrast, the networks extending in the frontal and parietal cortices, including the dorsal attention (DAN) and executive control (ECN) networks are thought to mediate externally-driven cognitive processes, including attention, inhibition and executive control, that support external awareness $(49,50)$. The frontoparietal networks increase in activity when attention is directed to external stimuli in cognitive tasks $(35,36,51,52)$.

Thus, although the relationship between the DMN and DAN/ECN to one another may depend upon the paradigm employed and the goals of the subject $(53,54)$, the juxtaposition 
of their functional time-courses is critical for the naturally ongoing switches between internal and external awareness (3133). As the DMN and fronto-parietal networks are juxtaposed to one another at rest (34-36), and dissociate further when attention is directed externally, we reasoned that their functional responses would be maximally juxtaposed to one another during a highly engaging stimulus.

In this study, we did not investigate internal awareness directly, but rather investigated the potential for internal as well as external awareness in DoC patients including patients in the vegetative and minimally conscious states. To this end, we asked whether the pattern of juxtaposition between the DMN and DAN/ECN functional time-courses observed in healthy controls $(31,55)$ was present in patients, who had previously demonstrated evidence of external awareness. To this end, we used the aforementioned highly engaging short movie by Alfred Hitchcock to drive the recruitment of the frontoparietal networks and its maximal disengagement from the DMN relative to the resting state baseline, in a control group of healthy participants and severely brain-injured patients with disorders of consciousness. To circumvent the limitations of behavioral testing based on the clinical evaluation and ensure that patients categorized as unconscious indeed showed no wilful brain responses, each patient underwent a functional Magnetic Resonance Imaging (fMRI)-based assessment with a previously established command-following protocol for detecting covert awareness $(5,56)$. Initially, we investigated the functional connectivity of the DMN and DAN/ECN in the healthy controls during movie viewing relative to the baseline conditions. Subsequently, we tested whether DoC patients, who demonstrated independent covert external awareness, differently from patients who did not, showed a juxtaposition between the DMN and fronto-parietal functional time-courses that was strengthened by the complex stimulus.

\section{METHODS}

\section{Participants}

Ethical approval was obtained from the Health Sciences Research Ethics Board and the Psychology Research Ethics Board of Western University, in London Canada. All healthy participants were right-handed, native English speakers and had no history of neurological disorders. They gave informed written consent and were remunerated for their time. Thirteen and twelve healthy volunteers participated in experiment 1 and 2, respectively. The data of healthy volunteers was previously reported in studies by Naci et al. $(7,18)$. A convenience sample of 18 DoC patients participated in experiment 3 . The patients' respective substitute decision makers provided informed written consent. Three patients were excluded from final analyses. Of these, one was excluded because of large structural brain damage and extremely enlarged ventricles that would have rendered any further analysis impossible. A second patient was excluded due to excessive movement in the scanner, which caused the termination of the scanning session. The third patient was excluded due to a "locked-in syndrome" diagnosis. Patient 1 appeared twice in the data set, with the corresponding two different scanning visits 2 years apart. In visit 1 , the patient showed the ability to perform the command following task in the scanner, whereas in visit 2 there was no evidence of command following. These differences may have been due to fluctuations in arousal or a genuine change in the patient's status of consciousness. Based on the results of the fMRI analysis, the patient's data from the 2 visits were treated as independent samples for the purpose of subsequence group analysis. Activitybased analyses on data from a subset of the patient cohort were previously reported in Naci et al. $(7,18)$ and Naci and Owen (5). Prior to commencing the scanning sessions, all patients were tested behaviorally at their bedside (outside of the scanner) with the Coma Recovery Scale-Revised (CRS-R) (57), which assessed each patient's behavioral responsivity along 6 sub-scales: auditory, visual, motor, oromotor/verbal, communication, and arousal (Table 1). All patients were clinically diagnosed as either VS or minimally conscious state [MCS; (30)] at the time of the image acquisition based on the CRS-R. Table 2 provides an overview of the demographic and clinical information, as well as the results of the fMRI command-following protocol for each patient.

\section{Stimuli and Design}

In experiment 1 , a group of healthy participants $(N=13)$ were scanned in two different conditions, resting state $(8 \mathrm{~min})$ and movie-viewing $(8 \mathrm{~min})$ in the same session. Participants were instructed to simply relax in the resting state, and to pay attention to the movie during the stimulation condition. The movie consisted of an edited version of Alfred Hitchcock's blackand-white movie "Bang! You're Dead." It depicted a 5-yearold boy, who finds his uncle's revolver, partially loads it with bullets, and plays with it at home and in public, unaware of its power and danger. Sound in the scanner was delivered over scanner-compatible noise canceling headphones.

In experiment 2 , healthy participants $(N=12)$ watched a visually and auditory scrambled version of the Hitchcock movie sequence inside the scanner. To create the scrambled condition, very brief (one second) audio-visual segments of the movie were pseudo-randomized, retaining the sensory properties (visual and auditory) while removing the narrative. Written feedback at the end of the scanning session confirmed that participants were not able to uncover a storyline in the scrambled movie, or relate it to stored knowledge of previous movies they had seen.

In experiment $3, \mathrm{DoC}$ patients $(N=15)$ were scanned in the resting state and during viewing of the intact movie in the same session. The condition order was counterbalanced and the same procedure and scanning parameters were used for the patients as for healthy controls. To control for patient's wakefulness, eye opening was monitored inside the scanner with an infrared camera. Due to the highly limited time in the scanner, severely brain-injured patients did not undergo the scrambled movie baseline condition.

\section{Patient Behavioral Assessment and Command-Following fMRI Paradigm}

Awareness fluctuates greatly in the chronic DoC patient group, and therefore the behavioral diagnosis based on the gold-standard measure of CRS-R is likely to fluctuate 
TABLE 1 | Coma Recovery Scale-Revised subscale scores assessed prior to the fMRI session.

\begin{tabular}{|c|c|c|c|c|c|c|c|}
\hline Patient ID & Diagnosis & Auditory & Visual & Motor & Oromotor/verbal & Communication & Arousal \\
\hline 1 Visit 1 & VS & 1 - Auditory startle & 0 - None. & 2 - Flexion withdrawal & 1 - Oral reflexive & 0 - None & $\begin{array}{l}2 \text { - Eye opening } \\
\text { without stimulation }\end{array}$ \\
\hline Visit 2 & VS & 1 - Auditory startle & 1 - Visual startle & 2 - Flexion withdrawal & 1 - Oral reflexive & 0 - None & $\begin{array}{l}2 \text { - Eye opening } \\
\text { without stimulation }\end{array}$ \\
\hline 2 & MCS & 1 - Auditory startle & 3 - Visual pursuit & 2 - Flexion withdrawal & 1 - Oral reflexive & 0 - None & $\begin{array}{l}2 \text { - Eye opening } \\
\text { without stimulation }\end{array}$ \\
\hline 3 & VS & 1 - Auditory startle & 1 - Visual startle & 1 - Abnormal posturing & 1 - Oral reflexive & 0 - None & $\begin{array}{l}2 \text { - Eye opening } \\
\text { without stimulation }\end{array}$ \\
\hline 4 & MCS & $\begin{array}{l}3 \text { - Reproducible } \\
\text { movement to } \\
\text { command }\end{array}$ & 3 - Visual pursuit & 2 - Flexion withdrawal & $\begin{array}{l}2 \text {-Vocaliza-tion/oral } \\
\text { movement }\end{array}$ & 0 - None & 3 - Attention \\
\hline 5 & MCS & 1 - Auditory startle & 3 - Visual pursuit & 2 - Flexion withdrawal & 1 - Oral reflexive & 0 - None & $\begin{array}{l}1 \text { - Eye opening } \\
\text { with stimulation }\end{array}$ \\
\hline 6 & VS & 1 - Auditory startle & 1 - Visual startle & 2 - Flexion withdrawal & 1 - Oral reflexive & 0 - None & $\begin{array}{l}1 \text { - Eye opening } \\
\text { with stimulation }\end{array}$ \\
\hline 7 & VS & 0 - None & 0 - None & 2 - Flexion withdrawal & 1 - Oral reflexive & 0 - None & $\begin{array}{l}2 \text { - Eye opening } \\
\text { without stimulation }\end{array}$ \\
\hline 8 & VS & $\begin{array}{l}2 \text { - Localization to } \\
\text { sound }\end{array}$ & 1 - Visual startle & 1 - Abnormal posturing & 0 - None & 0 - None & $\begin{array}{l}2 \text { - Eye opening } \\
\text { without stimulation }\end{array}$ \\
\hline 9 & VS & 0 - None & 1 - Visual startle & 0 - None & 0 - None & 0 - None & $\begin{array}{l}2 \text { - Eye opening } \\
\text { without stimulation }\end{array}$ \\
\hline 10 & MCS & $\begin{array}{l}2 \text { - Localization to } \\
\text { sound }\end{array}$ & 3 - Visual pursuit & 1 - Abnormal posturing & 1 - Oral reflexive & 0 - None & $\begin{array}{l}2 \text { - Eye opening } \\
\text { without stimulation }\end{array}$ \\
\hline 11 & MCS & $\begin{array}{l}4 \text { - Consistent } \\
\text { movement to } \\
\text { command }\end{array}$ & $\begin{array}{l}4 \text { - Object } \\
\text { localization: } \\
\text { reaching }\end{array}$ & $\begin{array}{l}4 \text { - Automatic motor } \\
\text { response }\end{array}$ & 1 - Oral reflexive & $\begin{array}{l}1 \text { - Non-functional: } \\
\text { intentional }\end{array}$ & $\begin{array}{l}1 \text { - Eye opening } \\
\text { with stimulation }\end{array}$ \\
\hline 12 & VS & 1 - Auditory startle & 0 - None & 1 - Abnormal posturing & 1 - Oral reflexive & 0 - None & $\begin{array}{l}1 \text { - Eye opening } \\
\text { with stimulation }\end{array}$ \\
\hline 13 & VS & 1 - Auditory startle & 0 - None & 2 - Flexion withdrawal & 1 - Oral reflexive & 0 - None & $\begin{array}{l}1 \text { - Eye opening } \\
\text { with stimulation }\end{array}$ \\
\hline 14 & VS & 1 - Auditory startle & 1 - Visual startle & 0 - None & 1 - Oral reflexive & 0 - None & $\begin{array}{l}2 \text { - Eye opening } \\
\text { without stimulation }\end{array}$ \\
\hline 15 & MCS & 1 - Auditory startle & 3 - Visual pursuit & 1 - Abnormal posturing & 1 - Oral reflexive & 0 - None & $\begin{array}{l}1 \text { - Eye opening } \\
\text { with stimulation }\end{array}$ \\
\hline
\end{tabular}

VS, vegetative state; MCS, minimally conscious state.

(58). Furthermore, in some cases, as for CMD patients (59), awareness is difficult to spot behaviorally. Therefore, it was a priority of this manuscript to base evaluation of awareness on an assessment that would not falsely put covertly responding "VS patients" in a group of non-responders. Accordingly, to ensure an objective standard of awareness that was independent of the behavioral diagnosis, and also relevant but independent to the movie paradigm, awareness was assessed with a previously validated fMRI task (5) in the same scanning session as the movie paradigm.

To account for the variability of the behavioral diagnosis, we conducted on average 7 CRS-R assessments for each patient during the week of their research visit at our facility. Given this well-documented fluctuation, to follow as closely as possible the level of awareness that might be picked up by the fMRI task, here we reported the CRS-R score of the scanning day.

Each patient underwent a command following scan in the same scanning session. Stimuli. The stimuli were eleven single words ("one," "two," "three," "four," "five," "six," "seven," "eight," "nine," "yes," "no"). Design. The fMRI selective auditory attention paradigm has been previously described in healthy individuals (56) and patients with DoC (5), and is designed to identify the ability to follow commands to selectively attending to stimuli, by recruiting top-down attention. On each trial, participants were instructed to either count a target word ("yes" or "no") presented among pseudorandom distractors (spoken digits one to nine), or to relax. Each trial had an on/off design: sound ( $22.5 \mathrm{~s})$ followed by silence $(10 \mathrm{~s})$. The scan lasted $5 \mathrm{~min}$, including instructions.

As seen in Table 2, the results of the command following task were broadly consistent with the MCS patients' clinical diagnosis that indicated overt awareness-all but one MCS patient, who fell asleep in the scanner, were able to perform the selective attention task in the scanner [see $(60,61)$ for diverging results on MCS patients who could not perform a command-following task in the MRI scanner]. By contrast, 3 out of 10 VS patients showed positive command following results. This is consistent with previous findings showing that a proportion of patients 
TABLE 2 | The patients' demographic and clinical information, fMRI command-following protocol results and functional connectivity results.

\begin{tabular}{|c|c|c|c|c|c|c|c|c|}
\hline Patient ID & Age range & Diagnosis & $\begin{array}{l}\text { Interval since } \\
\text { ictus, months }\end{array}$ & $\begin{array}{l}\text { Score on } \\
\text { CRS-R }\end{array}$ & Etiology & $\begin{array}{l}\text { Command following } \\
\text { (attention) }\end{array}$ & $\begin{array}{l}\text { Movie DMN-DAN } \\
\text { Connectivity }\end{array}$ & $\begin{array}{l}\text { Resting DMN-DAN } \\
\text { Connectivity }\end{array}$ \\
\hline \multirow[t]{2}{*}{1} & $\begin{array}{l}\text { Visit 1: } \\
\text { 22-25 }\end{array}$ & VS & 67 & 6 & $\mathrm{TBI}$ & + & 0.21 & 0.32 \\
\hline & $\begin{array}{l}\text { Visit 2: } \\
\text { 26-30 }\end{array}$ & VS & 89 & 7 & & - & 0.38 & 0.32 \\
\hline 2 & $31-35$ & MCS & 445 & 9 & $\mathrm{HBI}$ & + & 0.44 & 0.48 \\
\hline 3 & $18-21$ & VS & 68 & 6 & $\mathrm{HBI}$ & - & 0.43 & 0.31 \\
\hline 4 & $26-30$ & MCS & 36 & 13 & $\mathrm{HBI}$ & + & 0.35 & 0.37 \\
\hline 5 & $46-50$ & MCS & 234 & 8 & $\mathrm{HBI}$ & + & 0.19 & 0.24 \\
\hline 6 & $56-60$ & VS & 38 & 6 & $\mathrm{HBI}$ & - & 0.37 & 0.13 \\
\hline 7 & $31-35$ & VS & 25 & 5 & $\mathrm{HBI}$ & - & 0.47 & 0.35 \\
\hline 8 & $18-21$ & VS & 3 & 6 & $\mathrm{HBI}$ & + & 0.29 & 0.46 \\
\hline 9 & $41-45$ & VS & 248 & 3 & TBI & + & 0.33 & 0.45 \\
\hline 10 & $22-25$ & MCS & 69 & 9 & TBI & + & 0.62 & 0.64 \\
\hline 11 & $46-50$ & MCS & 148 & 15 & $\mathrm{TBI}$ & - & 0.60 & 0.54 \\
\hline 12 & $51-55$ & VS & 11 & 4 & $\mathrm{HBI}$ & - & 0.63 & 0.64 \\
\hline 13 & $51-55$ & VS & 79 & 5 & $\mathrm{HBI}$ & - & 0.60 & 0.52 \\
\hline 14 & $18-21$ & VS & 49 & 5 & $\mathrm{HBI}$ & - & 0.66 & 0.25 \\
\hline 15 & $36-40$ & MCS & 38 & 7 & TBI & + & 0.13 & 0.38 \\
\hline
\end{tabular}

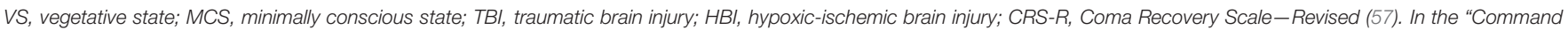

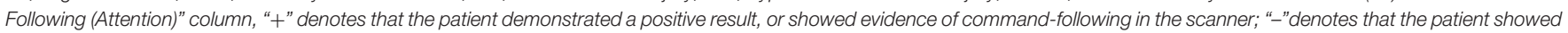

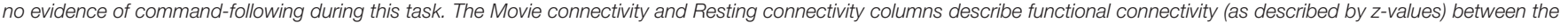
$D M N$ and DAN.

clinically diagnosed as VS are nevertheless able to modulate brain activity to command $(2,3,15)$. The results of this commandfollowing task were used to split the patient cohort into two groups: DoC + patients were able to perform the commandfollowing task in the scanner, DoC- patients were not able to do so. Further analyses were then performed independently for these two groups.

\section{Functional Data Acquisition}

All participants were scanned in a 3 Tesla Siemens Tim Trio MRI scanner at the Robarts Research Institute in London, Canada. A 32-channel head coil was used for functional and anatomical scans. We acquired functional images during movie viewing (246 scans) and resting-state (256 scans) by a T2*weighted echo-planar sequence [33 slices, voxel size $=3 \times 3$ $\times 3 \mathrm{~mm}^{3}$, interslice gap $=25 \%$, repetition time $=2,000 \mathrm{~ms}$, echo time $(\mathrm{TE})=30 \mathrm{~ms}$, matrix size $=64 \times 64$, flip angle $(\mathrm{FA})$ $=75$ degrees]. Furthermore, a T1-weighted 3D magnetization prepared rapid acquisition gradient echo (MPRAGE) sequence was used for anatomical scans [voxel size $=1 \times 1 \times 1 \mathrm{~mm}^{3}$, $\mathrm{TE}=4.25 \mathrm{~ms}$, matrix size $=240 \times 256 \times 192, \mathrm{FA}=9$ degrees $]$. The total anatomical scanning time was $5 \mathrm{~min} 38 \mathrm{sec}$. All scanning parameters were the same for healthy participants and patients.

\section{Preprocessing}

For preprocessing and data analysis we used SPM8 (Wellcome Institute of Cognitive Neurology, http://www.fil.ion.ucl.ac.uk/ spm/software/spm8/) and the AA pipeline software [(62), www. automaticanalysis.org]. All preprocessing and data analysis steps were the same for healthy participants and patients. We discarded the first five volumes of each run to avoid T1-saturation effects. The preprocessing procedure included slice-time correction, motion correction, normalization into Montreal Neurological Institute (MNI) space and spatial smoothing with a Gaussian kernel of $10 \mathrm{~mm}$ full width at half maximum. Furthermore, we applied a temporal high-pass filter with a cut-off of $1 / 128 \mathrm{~Hz}$ to each voxel and regressed out the six motion parameters ( $\mathrm{x}, \mathrm{y}, \mathrm{z}$, roll, pitch, yaw). To investigate any confounding effects of movement differences between groups and conditions, we additionally calculated the mean frame-wise displacement (63) for each participant and compared them using a mixed ANOVA, as well as paired $t$-tests. Healthy participants did not differ significantly in movement, as assessed by framewise displacement values, between the movie viewing and resting state condition $\left[t_{(12)}=-1.91, p=0.08\right]$. Similarly, the patients' movement did not differ significantly. A two-factor mixed ANOVA on motion, with factors group (DoC+, DoC-) and condition (movie, rest) showed no significant main effects [group: $F_{(1)}=0.28, p=0.60$; condition: $F_{(1)}=1.01, p=0.33$ ] and no significant interaction $\left[F_{(1,1)}=0.53, p=0.48\right]$. To avoid the formation of artificial anti-correlations, a confounding effect previously reported by Murphy et al. (64) and Anderson et al. (65), we performed no global signal regression.

\section{Functional Network Definition}

We analyzed functional connectivity within and between the three key networks that are involved in higher order processes: the DMN, DAN and ECN. The functional networks were 
defined based on functionally specific regions of interest (ROIs) (19 in total, $10 \mathrm{~mm}$ spheres), from well-established landmark coordinates published in Raichle (66). MNI coordinates for ROIs of each network can be found in Table 3. For the analysis of functional connectivity based on a set of network nodes predefined in the healthy literature (MNI standard neurological space), each patient's brain was normalized to the healthy template. Some of the ROIs may not be optimally located in a subset of the patients due to the varying location and extent of damage (see Figure $\mathbf{1}$ for an overview of structural information on the patients' brains). The mechanism of functional reorganization that follows brain injury and leads to loss of consciousness in some cases, whereas in others to preservation of consciousness, remains poorly understood and is the focus of active research $(59,67)$ outside of the scope of this manuscript. Therefore, although it is impossible to ascertain the structure-to-preserved function mapping for each individual patient, we expected that any damage within the regions of interest in each patient's brain would add noise to the brain activity measurement and reduce the power to detect an effect. Therefore, if results in brain-injured patients confirmed apriory hypotheses based on the healthy control group, they would likely present a conservative estimate of the underlying effect.

\section{Functional Connectivity Analysis}

The preprocessed mean BOLD time series of each ROI was extracted and correlated (Pearson correlation) with the time courses of all the other ROIs. We note that Pearson

TABLE 3 | Overview of the regions of interests for the DMN, DAN, and ECN.

\begin{tabular}{|c|c|c|c|c|}
\hline \multirow{2}{*}{$\begin{array}{l}\text { Network } \\
\text { Default mode } \\
\text { network }\end{array}$} & \multirow{2}{*}{$\begin{array}{l}\text { ROI } \\
\text { Posterior } \\
\text { cingulate/precuneus }\end{array}$} & \multicolumn{3}{|c|}{ MNI coordinates } \\
\hline & & 0 & -52 & 27 \\
\hline & Medial prefrontal & -1 & 54 & 27 \\
\hline & Left lateral parietal & -46 & -66 & 30 \\
\hline & Right lateral parietal & 49 & -63 & 33 \\
\hline & Left inferior temporal & -61 & -24 & -9 \\
\hline & Right inferior temporal & 58 & -24 & -9 \\
\hline \multirow{8}{*}{$\begin{array}{l}\text { Dorsal attention } \\
\text { network }\end{array}$} & Left frontal eye field & -29 & -9 & 54 \\
\hline & Right frontal eye field & 29 & -9 & 54 \\
\hline & Left posterior IPS & -26 & -66 & 48 \\
\hline & Right posterior IPS & 26 & -66 & 48 \\
\hline & Left anterior IPS & -44 & -39 & 45 \\
\hline & Right anterior IPS & 41 & -39 & 45 \\
\hline & Left MT & -50 & -66 & -6 \\
\hline & Right MT & 53 & -63 & -6 \\
\hline \multirow{5}{*}{$\begin{array}{l}\text { Executive control } \\
\text { network }\end{array}$} & Dorsal medial PFC & 0 & 24 & 46 \\
\hline & Left anterior PFC & -44 & 45 & 0 \\
\hline & Right anterior PFC & 44 & 45 & 0 \\
\hline & Left superior parietal & -50 & -51 & 45 \\
\hline & Right superior parietal & 50 & -51 & 45 \\
\hline
\end{tabular}

IPS, Intraparietal sulcus; MT, Middle temporal area; PFC, Prefrontal cortex. correlation is a basic FC measure that, while it does not directly imply causal relations between neural regions, is advantageous for its minimal assumptions regarding the true nature of brain interactions and breath of its use in the neuroscientific literature, and thus fitting to the aims of this investigation. Based on these Pearson's correlations, we created a $19 \times 19$ correlation matrix (Figure 2). We performed this procedure separately for the movie and resting state for each participant. The average over all ROIs within a network was computed and a two-way repeated measures ANOVA and Bonferroni-corrected pairwise comparisons were performed to evaluate effects of interest. To account for the non-normalized distribution of correlation values (68), all statistical analyses were performed on z-transformed correlation values, using Fisher's r-to-z transformation. For visualization purposes, we re-transformed these $z$-values in correlation values.

\section{RESULTS}

\section{Healthy Participants}

The correlation matrices for the movie viewing and resting state conditions, including all ROIs for the three networks, are shown in Figure 2. A two-way repeated measures ANOVA with factors condition (movie, rest) and connectivity (withinnetworks, between-networks) revealed a significant interaction effect $\left[F_{(1,1)}=18.52, p<0.001\right]$. During movie viewing the connectivity between the DMN and DAN $\left[t_{(12)}=4.58\right.$, $p<0.001]$ and DMN and ECN [ $t_{(12)}=4.03, p<0.005$ ] were significantly down-regulated during the movie relative to the resting state (Figure 3A). As the measure of connectivity (Pearson correlation) reflected the degree of similarity between the networks' functional time-courses, this result demonstrated that the functional response of each of the DAN/ECN became more dissimilar to that of the DMN during the movie relative to the resting state baseline. By comparison, functional connectivity between DAN and ECN $\left[t_{(12)}=0.23, p=0.82\right]$, as well as functional connectivity within the functional networks [DMN: $t_{(12)}=2.15, p=0.052$; DAN: $t_{(12)}=1.35, p=0.20$; ECN: $t_{(12)}$ $=0.75, p=0.47$ ] did not differ between the movie and resting state condition.

To further investigate whether this dissociation was indeed related to the processing of the movie's higher-order properties, including its narrative, or merely driven by the presence of sensory stimulation in the movie relative to the resting state condition, we investigated the connectivity between these networks during the intact movie relative to its scrambled version, which retained the sensory features but was devoid of the narrative (Figure 3B). Relative to the scrambled movie, in the intact movie we found significant down-regulation of the DMN-DAN connectivity $\left[t_{(11)}=-2.289, p<0.05\right]$, but not the DMN-ECN connectivity (Figure 3B). This suggested that the modulation of the DMN-DAN, but not DMN-ECN, connectivity during movie viewing reflected the processing of the movie's higher-order features, including its narrative. This result was consistent with a recent study showing heightened functional differentiation with increasing stimuli meaningfulness (69). 


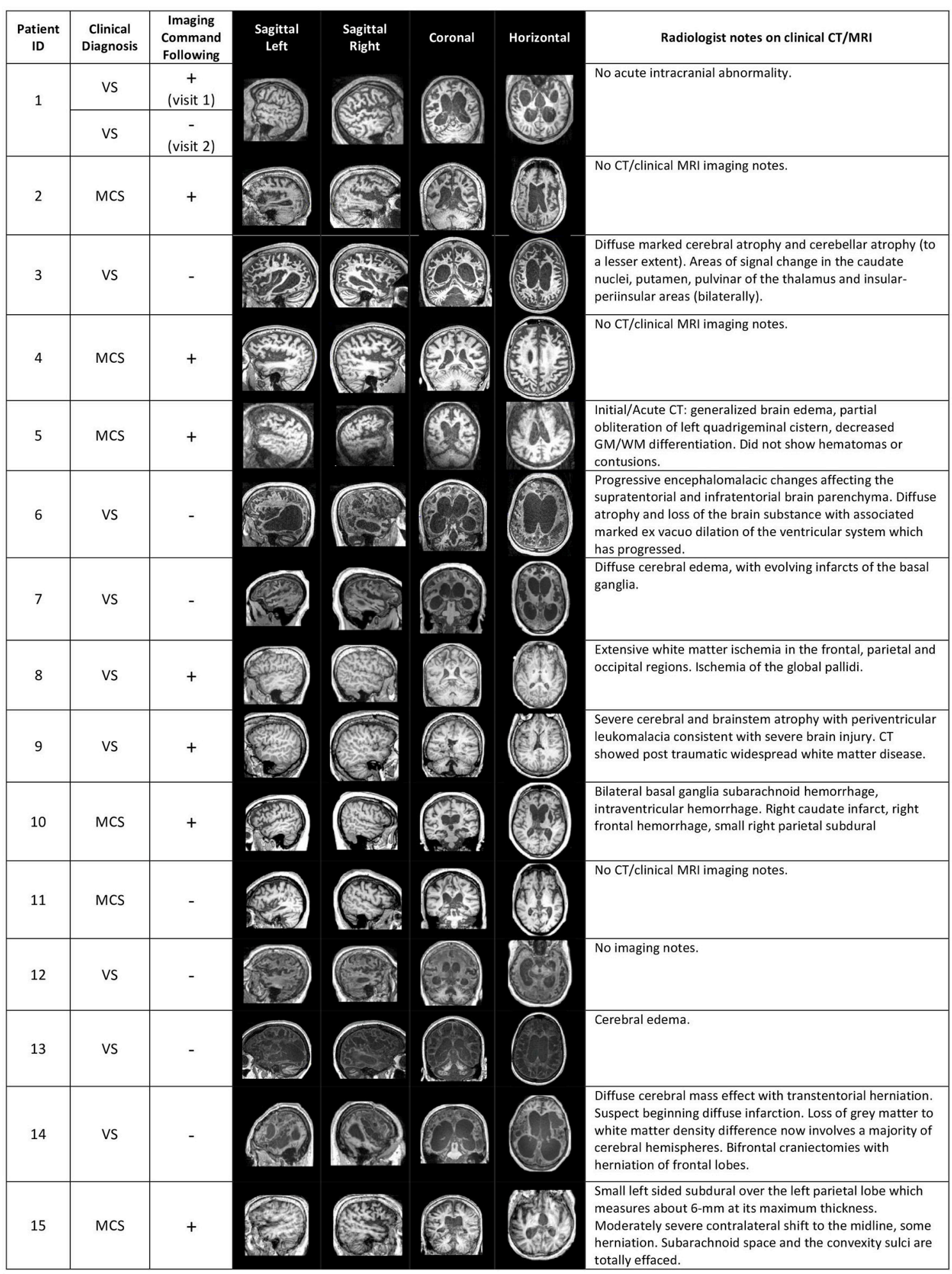

FIGURE 1 | Structural brain information for the patient cohort. Columns 4-7 give an overview of structural MRI images that were taken for each patient. On the right, clinical notes by radiologists on previous computerized tomography (CT) and/or MRI scans are listed. The sign "+" or "-" in the "Imaging Command Following" column describes whether the patient was able to successfully complete a command-following task in the MRI scanner (+), or not (-). 

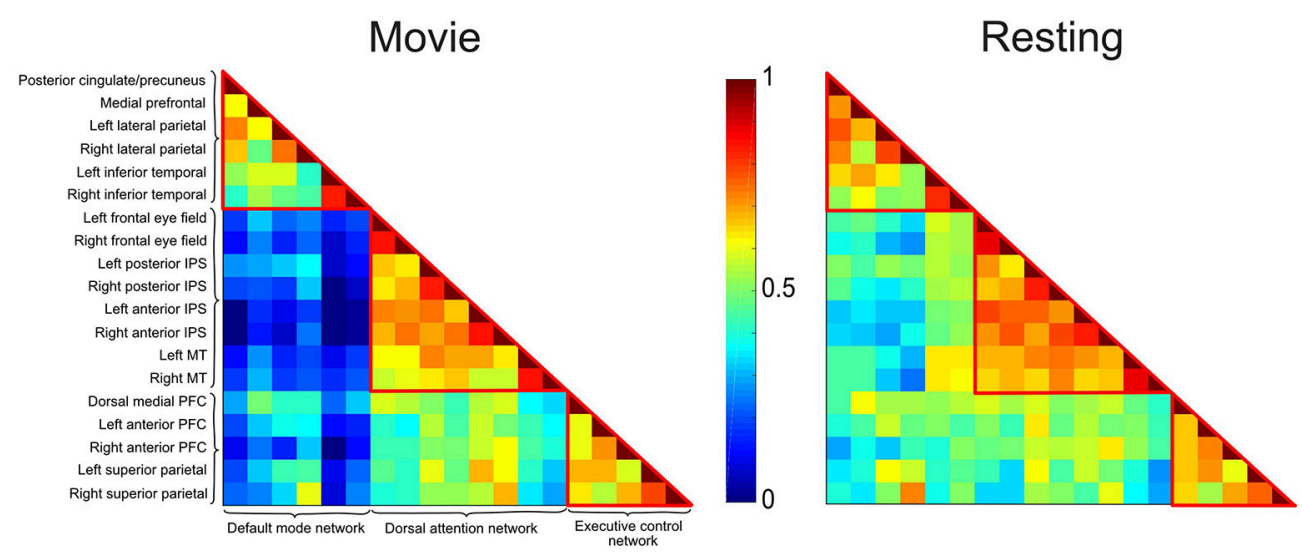

FIGURE 2 | Correlation matrices depicting the DMN, DAN, and ECN during movie viewing and resting state conditions in healthy participants. Each cell represents the color-coded connectivity between an ROI to itself (middle diagonal) or another region. The labels for the ROls in each network are displayed on the left-hand side. Warm/cool colors depict high/low correlations as per the heat bar in the middle of the graph. During movie viewing, healthy participants showed decreased functional connectivity between the DMN and the DAN/ECN as compared to the resting state. Functional connectivity within each network, and between the DAN and ECN did not differ significantly between the two conditions.
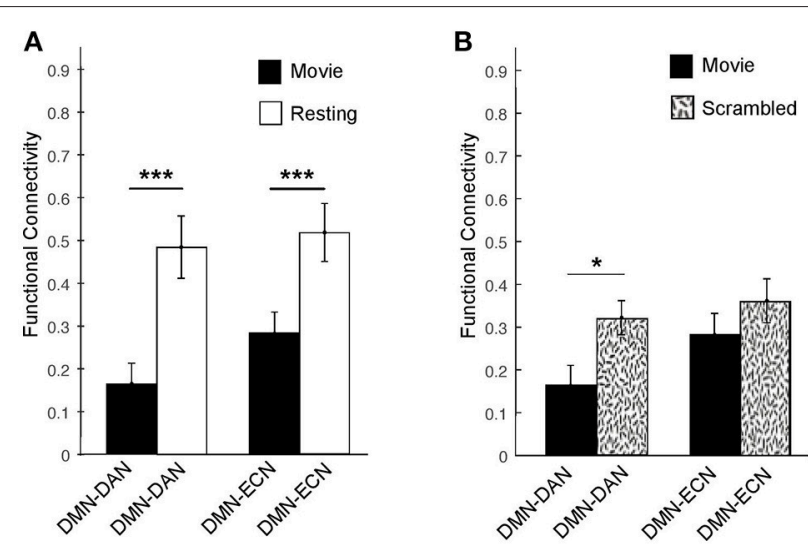

FIGURE 3 | Averaged functional connectivity between the DMN and DAN/ECN during the movie and baseline conditions in healthy participants. (A) During movie viewing, the DMN-DAN $\left[t_{(12)}=4.58, p<0.001\right]$ and the DMN-ECN $\left[t_{(12)}=4.03, p<0.005\right]$ connectivity was significantly down-regulated in healthy participants relative to the resting state. (B) The DMN-DAN $\left[t_{(11)}=-2.289, p<0.05\right]$, but not the DMN-ECN, connectivity was significantly down-regulated during the intact movie relative to its scrambled version, suggesting that the connectivity down-regulation was driven by the movie's higher-order properties including its narrative. ${ }^{*} p<0.05$, ${ }^{\star \star} p<0.01,{ }^{\star \star \star} p<0.005$.

\section{DoC Patients}

The results in the healthy controls suggested that the heightened differentiation between the DMN and DAN aspect of the fronto-parietal network was driven by the movie's high-order properties including its narrative. Subsequently, we investigated whether behaviorally non-responsive patients who retained covert external awareness (labeled here DoC+), and those who showed no such evidence (labeled here DoC-) [see command following (attention) in Table 2], showed heightened differentiation of the functional response of the DMN and DAN networks in response to movie viewing relative to their resting state baseline connectivity.

DoC + patients showed a significant down-regulation of DMN-DAN connectivity, suggesting heightened differentiation of the networks' functional response during the movie viewing relative to the resting state (Figure 4) $\left[t_{(7)}=-3.31, p<0.05\right]$. By contrast, DoC- patients showed no down-regulation of the DMN-DAN connectivity, but rather a significant up-regulation of this connectivity $\left[t_{(7)}=2.99, p<0.05\right]$ during the movie relative to the resting state.

The modulatory effect of movie viewing on the DMN-DAN connectivity was highly significant different between the two patient groups $\left[t_{(15)}=4.23, p=0.001\right.$; Figure 5A $]$. Moreover, the down-regulation of DMN-DAN connectivity in the DoC+ group, and the opposite effect in the DoC- group was visible in individual patient (Figure 5B), although, we caution that the current analysis is not optimized to investigate statistical significance at the single-subject level. By contrast, the DMNDAN connectivity during resting state did not differentiate the two patient types (Figures 5C,D).

\section{DISCUSSION}

In this study, we asked whether patients with disorders of consciousness retain the potential for internal as well as external conscious awareness. To address this question, we investigated the juxtaposed relationship between the DMN and frontoparietal (DAN, ECN) networks' functional time-courses, which are thought to support the naturally occurring fluctuations and dominance switching between internal and external awareness (31-33) in healthy individuals. We used a highly engaging external stimulus - a short movie by Alfred Hitchcock to drive maximal juxtaposition of the DMN and fronto-parietal networks relative to the resting state and scrambled, meaningless movie 

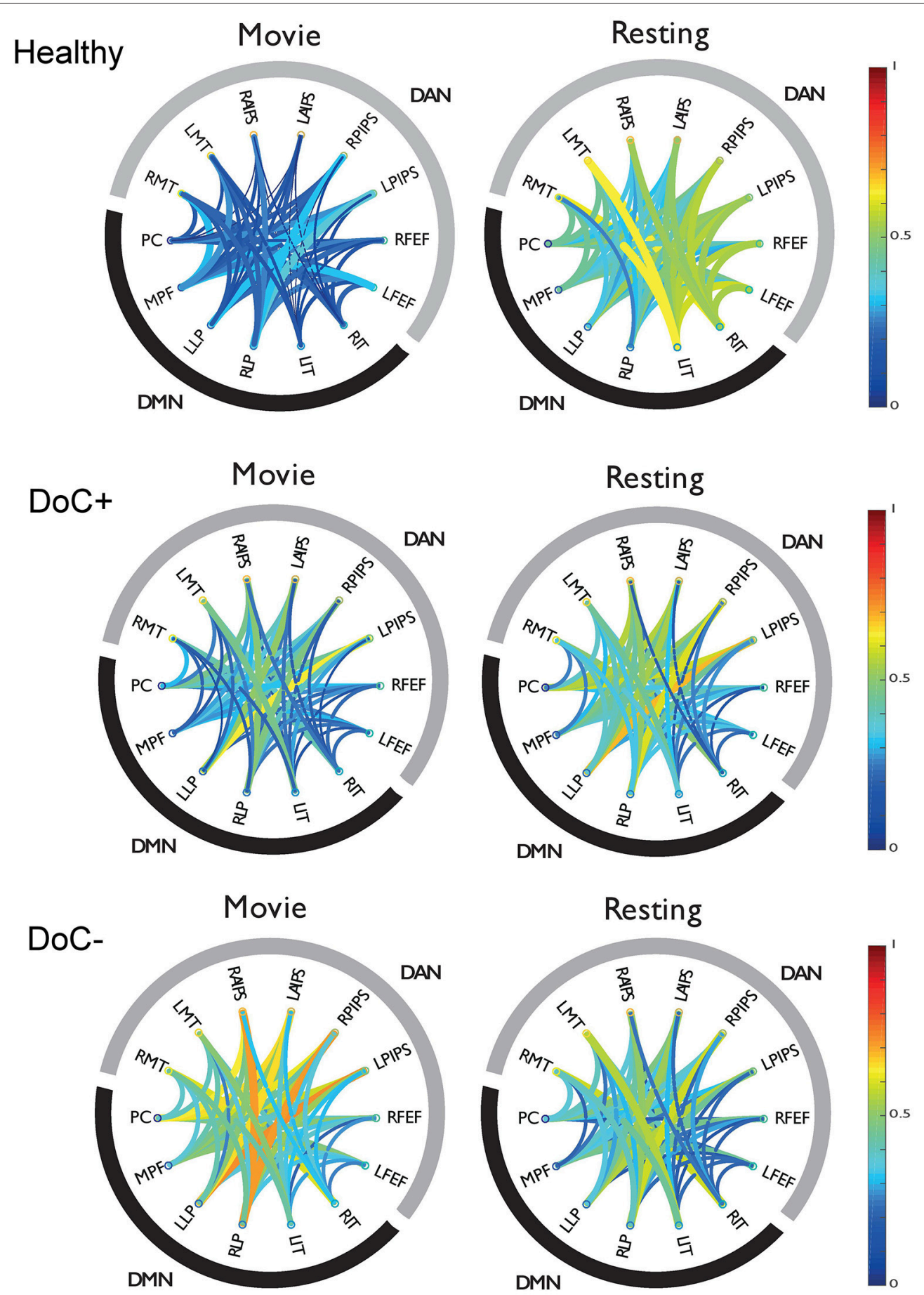

FIGURE 4 | DMN-DAN connectivity in healthy participants and DoC patients. The schema-balls provide an overview of individual ROI connectivity and depict all possible between-ROI connections for the DMN and DAN. Warm/cool colors depict high/low correlations as per the heat bar to the right of the graph. Healthy participants showed a down-regulation of DMN-DAN connectivity during movie viewing relative to the resting state. Similarly, the DoC+ patients showed a down-regulation of DMN-DAN connectivity during movie viewing $\left[t_{(7)}=-3.31, p<0.05\right]$. By contrast, DoC-patients did not show this effect. RMT, right middle temporal visual area; LMT, left middle temporal visual area; RAIPS, right anterior intraparietal sulcus; LAIPS, left anterior intraparietal sulcus; RPIPS, right posterior intraparietal sulcus; LPIPS, left posterior intraparietal sulcus; RFEF, right frontal eye field; LFEF, left frontal eye field; RIT, right inferior temporal; LIT, left inferior temporal; RLP, right lateral parietal; LLP, left lateral parietal; MPF, medial prefrontal; PC, posterior cingulate/precuneus. 

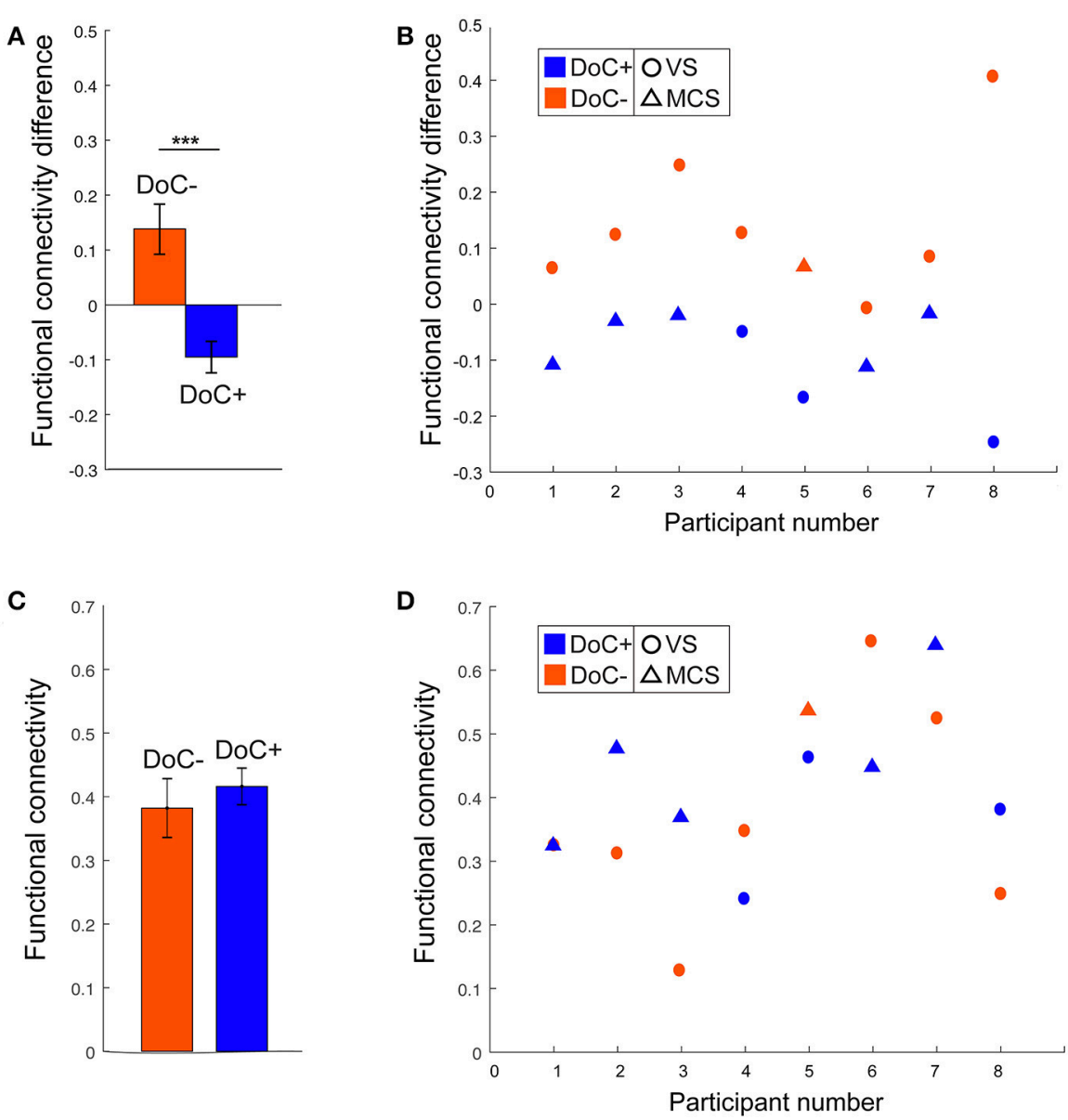

FIGURE 5 | DMN-DAN connectivity difference between movie viewing and the resting state and during resting state only in DoC patients. (A) The DoC+ and DoCgroups differed significantly on their DMN-DAN connectivity modulation during movie viewing relative to resting state $\left[t_{(15)}=4.23, p<0.005\right]$. (B) Visual inspection suggested that individual DoC+ patients displayed a down-regulation of DMN-DAN connectivity during movie viewing, illustrated by a negative value for the difference between movie and resting DMN-DAN connectivity. (C,D) During the resting state, there was no significant difference in DMN-DAN connectivity between the DoC+ and DoC- groups (C), and no such difference could be observed at the individual patient level (D). ${ }^{\star \star *} p<0.005$.

baseline conditions. Initially we investigated the connectivity between the DMN and fronto-parietal networks in response to movie viewing and baseline conditions in healthy controls, and subsequently, in two groups of severely brain-injured patients with DoC, one comprised of patients who demonstrated independent neuroimaging-based evidence of covert external awareness, and the other of those who did not.

Healthy controls showed significantly heightened differentiation between the DMN and the DAN in response to movie viewing relative to their resting state and scrambled movie time-courses. This result suggested that the heightened differentiation during movie viewing was driven by the movie's higher-order features, including its narrative. This finding was consistent with previous studies showing a heightened dissociation between the default mode and fronto-parietal networks on paradigms requiring externally-directed attention $[(48,52,55)$, but see $(70)$ for diverging results]. The connectivity between the DMN and ECN was not modulated by the movie's higher-order features, which may be explained by differential engagement by the movie paradigm of the DAN and ECN. Movie viewing required the ability to orient and sustain attention to the incoming auditory input, and discriminate the saliency and contextual relevance of the sensory inputs with respect to the evolving narrative-a function subserved primarily by the DAN (50), and it did not require behavioral response planning or monitoring - a function subserved primarily by the ECN (49).

Similar to healthy controls, severely brain-injured patients who had demonstrated independent evidence of covert external awareness showed significantly enhanced differentiation between the DMN and DAN functional time-course in response to movie viewing relative to the resting state baseline. This result suggested the presence of functional integrity in the default mode and fronto-parietal networks and their relationship to one another. It is worth noting that we did not investigate internal awareness directly, but rather the potential for internal awareness in addition to external awareness as indicated by the pattern of 
juxtaposed time-courses of these networks. Similar to the effect in healthy participants, these networks became more strongly juxtaposed to one another in response to movie viewing, relative to their resting baseline, suggesting the potential for internal as well as external awareness during complex stimulus processing.

By contrast, this effect was not present in chronic DoC patients who showed no fMRI-based evidence of covert awareness. Conversely, these patients showed a diminished differentiation between the DMN and DAN time-courses during the movie viewing relative to the resting state baseline. This was consistent with previous studies showing a loss of functional differentiation between brain networks in loss of consciousness (71-73). The loss of functional differentiation in response to movie viewing relative to the resting state suggests that, in severely brain-injured patients who likely lack conscious awareness, the stimulus-evoked feed-forward processing cascade is echoed undifferentiated throughout the brain leading to similar functional responses across different networks. In this study, we had no differential hypotheses for the MCS+ vs. MCSpatients and, on this basis, we did not differentiate between MCS patients. Further, the small number of MCS patients $(N=6)$ did not facilitate further separation into groups. However, it would be interesting to investigate in future studies differences between MCS + and MCS- patients in this regard, and we would hypothesize that MCS+ patients would be more likely than MCS- to show the heighted differentiation between the DMN and DAN networks during the movie paradigm relative to the resting state, which the current data suggest is indicative of the potential for internal awareness during viewing of a naturalistic narrative.

Visual inspection suggested that this effect was present at the single-subject level and differentiated patients who had covert awareness from those who did not, not only at the group but also at the individual level and thus, may be sufficiently robust to facilitate detection of covert awareness in individual patients in the absence of other neuroimaging assessments. This hypothesis requires formal testing with a large number of patients in future studies. Notably, this effect was not present when looking at DMN-DAN connectivity in the resting state alone, suggesting that richly evocative stimulation is appropriate for differentiating between behaviorally non-responsive patients who retain covert awareness and those who don't, based on the integrity of consciousness supporting networks. Previous studies have suggested several benefits of the movie-viewing paradigm over the resting state for investigating the functional integrity of brain networks in healthy individuals. Foremost, movie-viewing creates an immersive experience that naturally

\section{REFERENCES}

1. Owen AM, Coleman MR, Boly M, Davis MH, Laureys S, Pickard JD. Detecting awareness in the vegetative state. Science (2006) 313:1402. doi: 10.1126/science.1130197

2. Monti MM, Vanhaudenhuyse A, Coleman MR, Boly M, Pickard JD, Tshibanda L, et al. Willful modulation of brain activity in disorders of consciousness. $N$ Engl J Med. (2010) 362:579-89. doi: 10.1056/NEJMoa0905370 engages attention, rendering participants less likely to fall asleep and less liable to arousal fluctuations present in the resting state condition (74), it reduces movement $(19,75)$, and leads to strong brain activity $(21,22)$. Importantly, a complex and plot-driven naturalistic stimulus engages functionally distinct brain systems in a stereotypical way across different individuals $(7,17,18,20,21,23)$ that enables comparisons between different participants with minimized inter-subject variance with respect to specific perceptual and cognitive processes. Furthermore, the test-retest reliability of functional connectivity analyses during movie-viewing has been shown superior relative to the resting state, on average by $50 \%$ (76).

Our results suggest that these benefits extend to patient populations. To date, a large number of clinical studies investigating functional connectivity have focused on the resting state condition, due to its ease of acquisition in patient populations [e.g., (77-83)] and have provided significant insights on functional disruption in various populations relative to neurologically typical individuals. However, this approach cannot account for an important characteristic of healthy neural processing, that is, the brain's ability to re-organize its connectivity in response to external stimulation. Here, we show that naturalistic paradigms, which present complex realworld information evolving over time, can dissociate between groups of severely brain-injured chronic DoC patients with and without covert awareness, an approach that may also yield important insights when extended to other patient populations (84). Particularly, the ease of patient engagement with reduced movement and reduced arousal fluctuations is beneficial for testing a range of patient populations that, similarly to braininjured patients, exhibit large fluctuations in arousal, impaired motor control, and compromised attention span, and thus, are difficult to test with conventional paradigms that target cognition.

\section{AUTHOR CONTRIBUTIONS}

$\mathrm{AH}$ and LN: conceptualization; LN, AH, and RC: methodology; LG-L: patient recruitment; LN: data acquisition; $\mathrm{AH}$ and $\mathrm{LN}$ : formal analyses; $\mathrm{AH}$ and $\mathrm{LN}$ : manuscript preparation; BS and AO: feedback; LN: supervision.

\section{FUNDING}

This research was supported by a Canada Excellence Research Chair to AO and a L'Oréal-Unesco for Women in Science Excellence Research Grant to LN. 
5. Naci L, Owen AM. Making every word count for nonresponsive patients. JAMA Neurol. (2013) 70:1235-41. doi: 10.1001/jamaneurol.2013.3686

6. Fernández-Espejo D, Owen AM. Detecting awareness after severe brain injury. Nat Rev Neurosci. (2013) 14:801-9. doi: 10.1038/nrn3608

7. Naci L, Cusack R, Anello M, Owen AM. A common neural code for similar conscious experiences in different individuals. Proc Natl Acad Sci USA (2014) 111:14277-82. doi: 10.1073/pnas.1407007111

8. Bodien YG, Giacino JT, Edlow BL. Functional MRI motor imagery tasks to detect command following in traumatic disorders of consciousness. Front Neurol. (2017) 8:688. doi: 10.3389/fneur.2017.00688

9. PPlum F, Posner JB. The Diagnosis of Stupor and Coma, Vol. 19. Oxford: Oxford University Press (1982).

10. Laureys S, Owen AM, Schiff ND. Brain function in coma, vegetative state, and related disorders. The Lancet Neurology, (2004) 3, 537-546. doi: 10.1016/S1474-4422(04)00852-X

11. Owen AM. Disorders of consciousness. Ann N Y Acad Sci. (2008) 1124:22538. doi: 10.1196/annals.1440.013

12. The Multi-Society Task Force on PVS. Medical aspects of the persistent vegetative state. N Engl J Med. (1994) 330:1499-508. doi: 10.1056/NEJM199405263302107

13. Laureys S, Celesia GG, Cohadon F, Lavrijsen J, León-Carrión J, Sannita WG, et al. Unresponsive wakefulness syndrome: a new name for the vegetative state or apallic syndrome. BMC Med. (2010) 8:68. doi: 10.1186/1741-7015-8-68

14. Schnakers C, Vanhaudenhuyse A, Giacino J, Ventura M, Boly M, Majerus S, et al. Diagnostic accuracy of the vegetative and minimally conscious state: clinical consensus versus standardized neurobehavioral assessment. BMC Neurol. (2009) 9:35. doi: 10.1186/1471-2377-9-35

15. Kondziella D, Friberg CK, Frokjaer VG, Fabricius M, Møller K. Preserved consciousness in vegetative and minimal conscious states: systematic review and meta-analysis. J Neurol Neurosurg Psychiatry (2015) 87:485-92. doi: 10.1136/jnnp-2015-310958

16. Schiff ND. Cognitive motor dissociation following severe brain injuries. JAMA Neurol. (2015) 72:1413-5. doi: 10.1001/jamaneurol.2015.2899

17. Sinai L, Owen AM, Naci L. Mapping preserved real-world cognition in severely brain-injured patients. Front Biosci (Landmark Ed). (2017) 22:81523. doi: $10.2741 / 4518$

18. Naci L, Sinai L, Owen AM. Detecting and interpreting conscious experiences in behaviorally non-responsive patients. NeuroImage (2017) 145(Pt B):30413. doi: 10.1016/j.neuroimage.2015.11.059

19. Centeno M, Tierney TM, Perani S, Shamshiri EA, StPier K, Wilkinson $\mathrm{C}$, et al. Optimising EEG-fMRI for localisation of focal epilepsy in children. PLoS ONE (2016) 11:e0149048. doi: 10.1371/journal.pone. 0149048

20. Hasson U, Nir Y, Levy I, Fuhrmann G, Malach R. Intersubject synchronization of cortical activity during natural vision. Science (2004) 303:1634-40. doi: 10.1126/science.1089506

21. Bartels A, Zeki S. Brain dynamics during natural viewing conditions-a new guide for mapping connectivity in vivo. Neuroimage (2005) 24:339-49. doi: 10.1016/j.neuroimage.2004.08.044

22. Bartels A, Zeki S, Logothetis NK. Natural vision reveals regional specialization to local motion and to contrast-invariant, global flow in the human brain. Cereb Cortex (2007) 18:705-17. doi: 10.1093/cercor/bhm107

23. Hasson U, Malach R,Heeger DJ. Reliability of cortical activity during natural stimulation. Trends Cogn Sci. (2010) 14:40-8. doi: 10.1016/j.tics.2009.10.011

24. Naci L, Graham M, Owen AM, Weijer C. Covert narrative capacity: mental life in patients thought to lack consciousness. Ann Clin Transl Neurol. (2017) 4:61-70. doi: 10.1002/acn3.376

25. Sauseng P, Klimesch W, Schabus M, Doppelmayr M. Fronto-parietal EEG coherence in theta and upper alpha reflect central executive functions of working memory. Int J Psychophysiol. (2005) 57:97-103. doi: 10.1016/j.ijpsycho.2005.03.018

26. Hampshire A, Owen AM. Fractionating attentional control using eventrelated fMRI. Cereb Cortex (2006) 16:1679-89. doi: 10.1093/cercor/bhj116

27. Duncan J. The multiple-demand (MD) system of the primate brain: mental programs for intelligent behaviour. Trends Cogn Sci. (2010) 14:172-9. doi: 10.1016/j.tics.2010.01.004

28. Ptak R, Schnider A. The attention network of the human brain: relating structural damage associated with spatial neglect to functional imaging correlates of spatial attention. Neuropsychologia (2011) 49:3063-70. doi: 10.1016/j.neuropsychologia.2011.07.008

29. Barbey AK, Colom R, Solomon J, Krueger F, Forbes C, Grafman J. An integrative architecture for general intelligence and executive function revealed by lesion mapping. Brain (2012) 135:1154-64. doi: 10.1093/brain/aws021

30. Giacino JT, Ashwal S, Childs N, Cranford R, Jennett B, Katz DI, et al. The minimally conscious state definition and diagnostic criteria. Neurology (2002) 58:349-53. doi: 10.1212/WNL.58.3.349

31. Vanhaudenhuyse A, Demertzi A, Schabus M, Noirhomme Q, Bredart S, Boly $\mathrm{M}$, et al. Two distinct neuronal networks mediate the awareness of environment and of self. J Cogn Neurosci. (2011) 23:570-8. doi: 10.1162/jocn.2010.21488

32. Heine L, Soddu A, Gómez F, Vanhaudenhuyse A, Tshibanda L, Thonnard $\mathrm{M}$, et al. Resting state networks and consciousness: alterations of multiple resting state network connectivity in physiological, pharmacological, and pathological consciousness states. Front Psychol. (2012) 3:195. doi: 10.3389/fpsyg.2012.00295

33. Demertzi A, Soddu A, Laureys S. Consciousness supporting networks. Curr Opin Neurobiol. (2013) 23:239-44. doi: 10.1016/j.conb.2012.12.003

34. Greicius MD, Krasnow B, Reiss AL, Menon V. Functional connectivity in the resting brain: a network analysis of the default mode hypothesis. Proc Nat Acad Sci USA. (2003) 100:253-8. doi: 10.1073/pnas.0135058100

35. Fox MD, Snyder AZ, Vincent JL, Corbetta M, Van Essen DC, Raichle ME. The human brain is intrinsically organized into dynamic, anticorrelated functional networks. Proc Natl Acad Sci USA. (2005) 102:9673-8. doi: $10.1073 /$ pnas.0504136102

36. Sridharan D, Levitin DJ, Menon V. A critical role for the right fronto-insular cortex in switching between central-executive and default-mode networks. Proc Natl Acad Sci USA. (2008) 105:12569-74. doi: 10.1073/pnas.0800005105

37. Spreng RN, DuPre E, Selarka D, Garcia J, Gojkovic S, Mildner J, et al. Goalcongruent default network activity facilitates cognitive control. J Neurosci. (2014) 34:14108-14. doi: 10.1523/JNEUROSCI.2815-14.2014

38. Vatansever D, Menon DK, Manktelow AE, Sahakian BJ, Stamatakis EA. Default mode dynamics for global functional integration. J Neurosci. (2015) 35:15254-62. doi: 10.1523/JNEUROSCI.2135-15.2015

39. Vatansever D, Menon DK, Stamatakis EA. Default mode contributions to automated information processing. Proc Natl Acad Sci USA. (2017) 114:12821-6. doi: 10.1073/pnas.1710521114

40. Gusnard DA, Akbudak E, Shulman GL, Raichle ME. Medial prefrontal cortex and self-referential mental activity: relation to a default mode of brain function. Proc Natl Acad Sci USA. (2001) 98:4259-64. doi: 10.1073/pnas.071043098

41. Wicker B, Ruby P, Royet JP, Fonlupt P. A relation between rest and the self in the brain? Brain Res Rev. (2003) 43:224-30. doi: 10.1016/j.brainresrev.2003.08.003

42. D'argembeau A, Collette F, Van der Linden M, Laureys S, Del Fiore G, Degueldre C, et al. Self-referential reflective activity and its relationship with rest: a PET study. Neuroimage (2005) 25:616-24. doi: 10.1016/j.neuroimage.2004.11.048

43. Beer JS. The default self: feeling good or being right? Trends Cogn Sci. (2007) 11:187-9. doi: 10.1016/j.tics.2007.02.004

44. Buckner RL, Andrews-Hanna JR, Schacter DL. The brain's default network. Ann N Y Acad Sci. (2008) 1124:1-38. doi: 10.1196/annals.1440.011

45. Schneider F, Bermpohl F, Heinzel A, Rotte M, Walter M, Tempelmann C, et al. The resting brain and our self: self-relatedness modulates resting state neural activity in cortical midline structures. Neuroscience (2008) 157:120-31. doi: 10.1016/j.neuroscience.2008.08.014

46. Andrews-Hanna JR, Reidler JS, Sepulcre J, Poulin R, Buckner RL. Functionalanatomic fractionation of the brain's default network. Neuron (2010) 65:550 62. doi: 10.1016/j.neuron.2010.02.005

47. Raichle ME, MacLeod AM, Snyder AZ, Powers WJ, Gusnard DA, Shulman GL. A default mode of brain function. Proc Natl Acad Sci USA. (2001) 98:676-82. doi: 10.1073/pnas.98.2.676

48. Shulman GL, Fiez JA, Corbetta M, Buckner RL, Miezin FM, Raichle ME, et al. Common blood flow changes across visual tasks: II. Decreases in cerebral cortex. J Cogn Neurosci. (1997) 9:648-63. doi: 10.1162/jocn.1997.9. 5.648 
49. Kroger JK, Sabb FW, Fales CL, Bookheimer SY, Cohen MS, Holyoak KJ. Recruitment of anterior dorsolateral prefrontal cortex in human reasoning: a parametric study of relational complexity. Cereb Cortex (2002) 12:477-85. doi: $10.1093 /$ cercor/12.5.477

50. Corbetta M, Shulman GL. Control of goal-directed and stimulus-driven attention in the brain. Nat Rev Neurosci. (2002) 3:201-15. doi: 10.1038/nrn755

51. Seeley WW, Menon V, Schatzberg AF, Keller J, Glover GH, Kenna $\mathrm{H}$, et al. Dissociable intrinsic connectivity networks for salience processing and executive control. J Neurosci. (2007) 27:2349-56. doi: 10.1523/JNEUROSCI.5587-06.2007

52. Dosenbach NU, Fair DA, Miezin FM, Cohen AL, Wenger KK, Dosenbach RA, et al. Distinct brain networks for adaptive and stable task control in humans. Proc Natl Acad Sci USA. (2007) 104:11073-8. doi: 10.1073/pnas.0704320104

53. Spreng RN, Stevens WD, Chamberlain JP, Gilmore AW, Schacter DL. Default network activity, coupled with the frontoparietal control network, supports goal-directed cognition. Neuroimage (2010) 53:303-17. doi: 10.1016/j.neuroimage.2010.06.016

54. Smallwood J, Brown K, Baird B, Schooler JW. Cooperation between the default mode network and the frontal-parietal network in the production of an internal train of thought. Brain Res. (2012) 1428:60-70. doi: 10.1016/j.brainres.2011.03.072

55. Kelly AC, Uddin LQ, Biswal BB, Castellanos FX, Milham MP. Competition between functional brain networks mediates behavioral variability. Neuroimage (2008) 39:527-537. doi: 10.1016/j.neuroimage.2007.08.008

56. Naci L, Cusack R, Jia VZ, Owen AM. The brain's silent messenger: using selective attention to decode human thought for brain-based communication. J Neurosci. (2013) 33:9385-93. doi: 10.1523/JNEUROSCI.5577-12.2013

57. Giacino JT, Kalmar K, Whyte J. The JFK coma recovery scale-revised: measurement characteristics and diagnostic utility. Arch Phys Med Rehabil. (2004) 85:2020-29. doi: 10.1016/j.apmr.2004.02.033

58. Wannez S, Heine L, Thonnard M, Gosseries O, Laureys S, Coma Science Group Collaborators. The repetition of behavioral assessments in diagnosis of disorders of consciousness. Ann Neurol. (2017) 81:883-9. doi: 10.1002/ana.24962

59. Schiff ND. Altered consciousness. In: Winn R, editor. Youmans and Winn's Neurological Surgery, 7th Edn. New York, NY: Elsevier Saunders (2016). p. $203-8$

60. Monti MM, Coleman MR, Owen AM. Executive functions in the absence of behavior: functional imaging of the minimally conscious state. Prog Brain Res. (2009) 117:249-60. doi: 10.1016/S0079-6123(09)17717-8

61. Monti MM, Rosenberg M, Finoia P, Kamau E, Pickard JD, Owen AM. Thalamo-frontal connectivity mediates top-down cognitive functions in disorders of consciousness. Neurology (2015) 85:1-7. doi: 10.1212/WNL.0000000000001123

62. Cusack R, Vicente-Grabovetsky A, Mitchell DJ, Wild CJ, Auer T, Linke $\mathrm{AC}$, et al. Automatic analysis (aa): efficient neuroimaging workflows and parallel processing using Matlab and XML. Front Neuroinform. (2015) 8:90. doi: 10.3389/fninf.2014.00090

63. Power JD, Barnes KA, Snyder AZ, Schlaggar BL, Petersen SE. Spurious but systematic correlations in functional connectivity MRI networks arise from subject motion. Neuroimage (2012) 59:2142-54. doi: 10.1016/j.neuroimage.2011.10.018

64. Murphy K, Birn RM, Handwerker DA, Jones TB, Bandettini PA. The impact of global signal regression on resting state correlations: are anti-correlated networks introduced? Neuroimage (2009) 44:893-905. doi: 10.1016/j.neuroimage.2008.09.036

65. Anderson JS, Druzgal TJ, Lopez-Larson M, Jeong EK, Desai K, Yurgelun-Todd D. Network anticorrelations, global regression, and phase-shifted soft tissue correction. Hum Brain Mapp. (2011) 32:919-34. doi: 10.1002/hbm.21079

66. Raichle ME. The restless brain. Brain Connect. (2011) 1:3-12. doi: 10.1089/brain.2011.0019

67. Fernández-Espejo D, Rossit S, Owen AM. A thalamocortical mechanism for the absence of overt motor behavior in covertly aware patients. JAMA Neurol. (2015) 72:1442-50. doi: 10.1001/jamaneurol.2015.2614

68. Fisher RA. Frequency distribution of the values of the correlation coefficient in samples from an indefinitely large population. Biometrika (1915) 10:507-21. doi: $10.2307 / 2331838$
69. Boly M, Sasai S, Gosseries O, Oizumi M, Casali A, Massimini M, et al. Stimulus set meaningfulness and neurophysiological differentiation: a functional magnetic resonance imaging study. PLoS ONE (2015) 10:e0125337. doi: 10.1371/journal.pone.0125337

70. Elton A, Gao W. Task-positive functional connectivity of the default mode network transcends task domain. J Cogn Neurosci. (2015) 27:2369-81. doi: 10.1162/jocn_a_00859

71. Stamatakis EA, Adapa RM, Absalom AR, Menon DK. Changes in resting neural connectivity during propofol sedation. PLoS ONE (2010) 5:e14224. doi: 10.1371/journal.pone.0014224

72. Massimini M, Ferrarelli F, Sarasso S, Tononi G. Cortical mechanisms of loss of consciousness: insight from TMS/EEG studies. Arch Ital Biol. (2012) 150:44-55. doi: 10.4449/aib.v150i2.1361

73. Casali AG, Gosseries O, Rosanova M, Boly M, Sarasso S, Casali KR, et al. A theoretically based index of consciousness independent of sensory processing and behavior. Sci Transl Med. (2013) 5:198ra105. doi: 10.1126/scitranslmed.3006294

74. Tagliazucchi E, Laufs H. Decoding wakefulness levels from typical fMR resting-state data reveals reliable drifts between wakefulness and sleep. Neuron (2014) 82:695-708. doi: 10.1016/j.neuron.2014.03.020

75. Vanderwal T, Kelly C, Eilbott J, Mayes LC, Castellanos FX. (2015). Inscapes: a movie paradigm to improve compliance in functional magnetic resonance imaging. NeuroImage 122:222-32. doi: 10.1016/j.neuroimage.2015.07.069

76. Wang J, Ren Y, Hu X, Nguyen VT, Guo L, Han J, et al. Test-retest reliability of functional connectivity networks during naturalistic fMRI paradigms. Hum Brain Mapp. (2017) 38:2226-41. doi: 10.1002/hbm.23517

77. Sorg C, Riedl V, Mühlau M, Calhoun VD, Eichele T, Läer L, et al. Selective changes of resting-state networks in individuals at risk for Alzheimer's disease. Proc Natl Acad Sci USA. (2007) 104:18760-5. doi: 10.1073/pnas.0708803104

78. Greicius M. Resting-state functional connectivity in neuropsychiatric disorders. Curr Opin Neurol. (2008) 21:424-30. doi: 10.1097/WCO.0b013e328306f2c5

79. Boly M, Tshibanda L, Vanhaudenhuyse A, Noirhomme Q, Schnakers C, Ledoux D, et al. Functional connectivity in the default network during resting state is preserved in a vegetative but not in a braindead patient. Hum Brain Mapp. (2009) 30:2393-400. doi: 10.1002/hbm.20672

80. Rosazza C, Minati L. Resting-state brain networks: literature review and clinical applications. Neurol Sci. (2011) 32:773-85. doi: 10.1007/s10072-011-0636-y

81. Soddu A, Vanhaudenhuyse A, Demertzi A, Bruno MA, Tshibanda L, Di H, et al. Resting state activity in patients with disorders of consciousness. Funct Neurol. (2011) 26:37.

82. Lee MH, Smyser CD, Shimony JS. Resting-state fMRI: a review of methods and clinical applications. Amer J Neuroradiol. (2013) 34:1866-72. doi: 10.3174/ajnr.A3263

83. Hannawi Y, Lindquist MA, Caffo BS, Sair HI, Stevens RD. Resting brain activity in disorders of consciousness A systematic review and meta-analysis. Neurology (2015) 84:1272-80. doi: 10.1212/WNL.0000000000001404

84. Hasson U, Avidan G, Gelbard H, Vallines I, Harel M, Minshew N, et al. Shared and idiosyncratic cortical activation patterns in autism revealed under continuous real-life viewing conditions. Autism Res. (2009) 2:220-31. doi: 10.1002/aur.89

Conflict of Interest Statement: The authors declare that the research was conducted in the absence of any commercial or financial relationships that could be construed as a potential conflict of interest.

The reviewer MM declared a past co-authorship with one of the authors AO to the handling Editor.

Copyright (C) 2018 Haugg, Cusack, Gonzalez-Lara, Sorger, Owen and Naci. This is an open-access article distributed under the terms of the Creative Commons Attribution License (CC BY). The use, distribution or reproduction in other forums is permitted, provided the original author(s) and the copyright owner are credited and that the original publication in this journal is cited, in accordance with accepted academic practice. No use, distribution or reproduction is permitted which does not comply with these terms. 